www.jmscr.igmpublication.org

Impact Factor (SJIF): 6.379

Index Copernicus Value: 79.54

ISSN (e)-2347-176x ISSN (p) 2455-0450

crossrefDOI: https://dx.doi.org/10.18535/jmscr/v6i8.183

Journal Of Medical Science And Clinical Research

\title{
Rare Case of Adult Onset Cervical Cystic Hygroma: A Case Report
}

\author{
Authors \\ Dr Saurabh Singh, Dr Vivek Maurya \\ Department of General Surgery-Saraswati Medical College \\ Address: LIDA, Mahu Vihar, P.O. Asha Khera, NH- 25, Lucknow- Kanpur Highway \\ Unnao (UP), Pin 209859, India
}

\section{Introduction}

Cystic hygroma is a malformation of the lymphatic vessels. They commonly present in younger age group up to 2 years ${ }^{1}$. Presentation in adulthood is rare and the cause is uncertain, although trauma and upper respiratory tract infection have both been suggested as possible triggers for ${ }^{2}$. The most common site is posterior triangle of neck around $80 \%$ other site are axilla, groin, mediastinum. They are multiseptate and brilliant transilluminant so called hydrocele of neck $^{3}$.

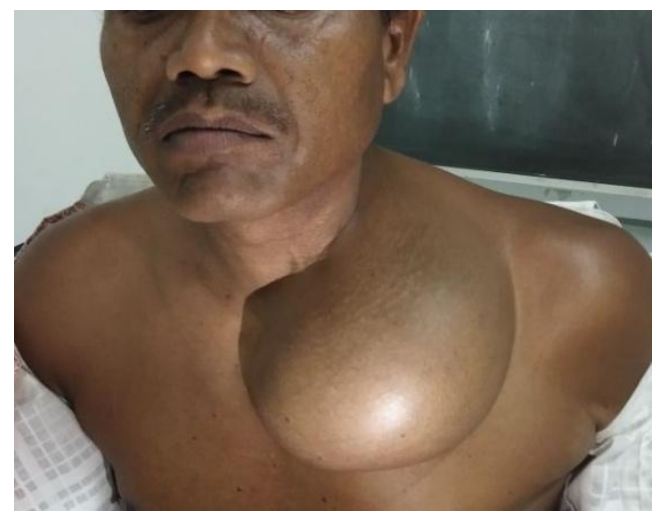

Fig. 1

\section{Case Report}

A 51-year-old male presented with a painless cystic swelling in left posterior triangle of neck for last one year. Patient did not give any history of trauma or upper respiratory tract infection during examination cystic swelling $15 \times 20 \mathrm{~cm}$ with brilliant transilluminat. The swelling was nontender, non fluctuant, brilliantly translucent extending into both anterior and posterior triangle of the neck.

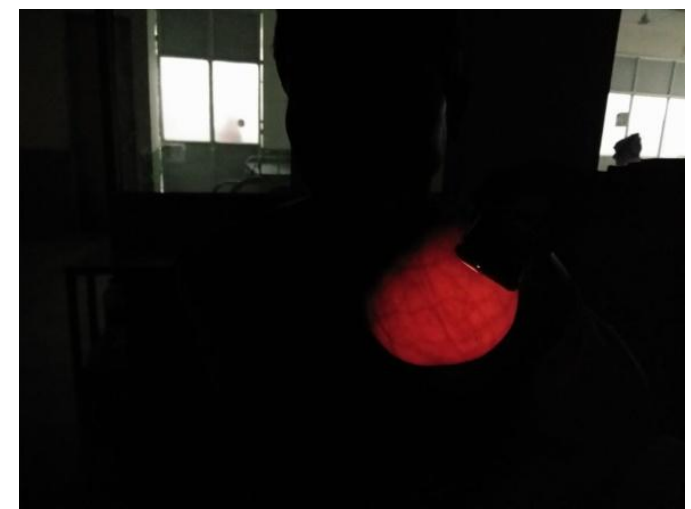

Fig. 2

A 51-year- man presenting with a large left-sided cervical swellin (Fig. 1) and transillumination (Fig. 2). 


\section{JMSCR Vol||06||Issue||08||Page 1108-1111||August}

\section{Investigations}

Ultrasonographic findings- revealed a multilobular cystic swelling that extended from the suboccipital region to the postauricular region. CECT imaging- findings showed a multilobular cystic mass with a size of $15 \times 20 \mathrm{~cm}$ extending from the posterior border of the sternocleidom- astoid muscle to the prevertiberal facia and anterior chest wall up to $2_{\text {nd }}$ intercostals space (Figure 2).

Fine-needle aspiration cytology- demonstrated a cystic lesion, and the diagnosis was lymphangioma.

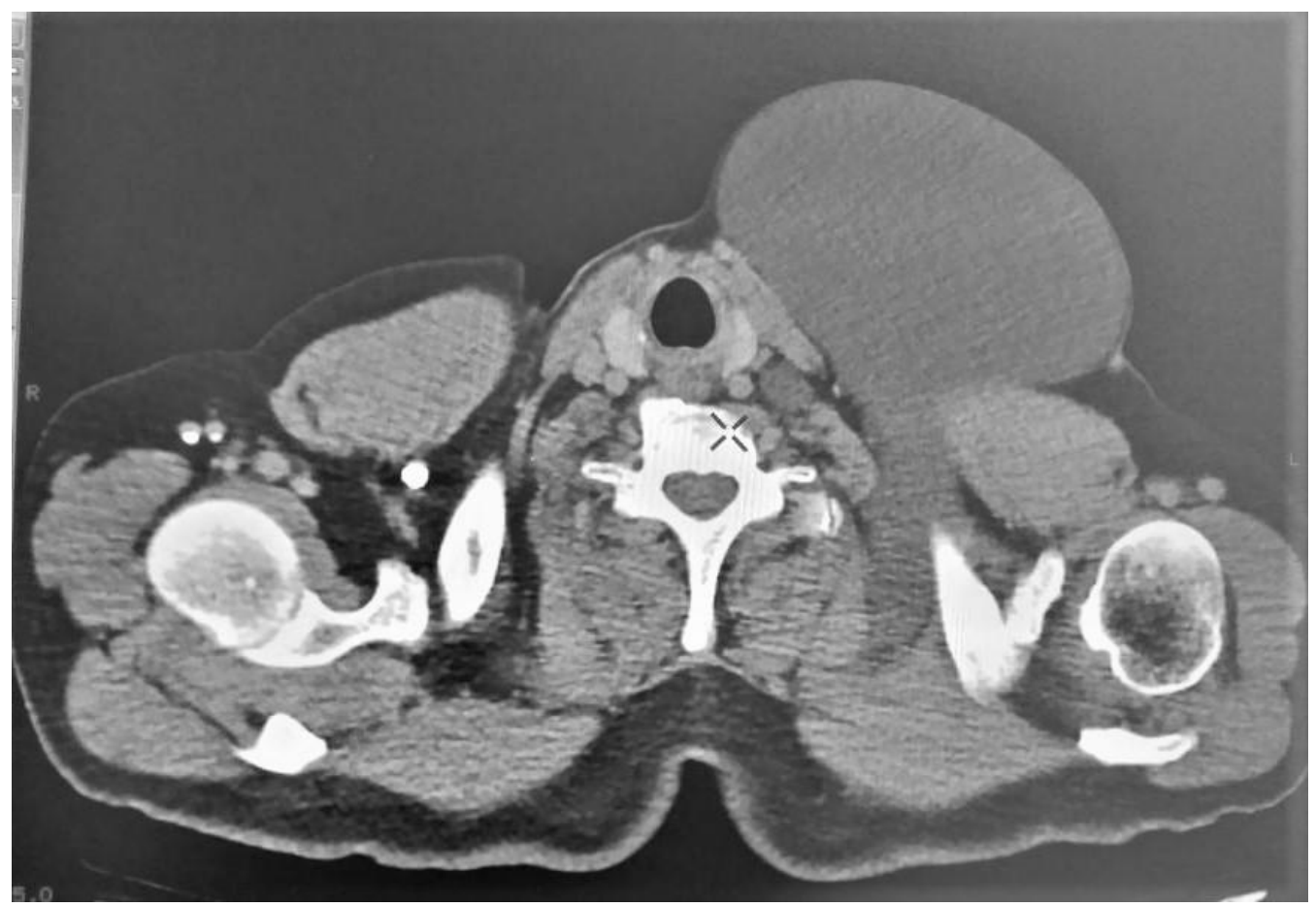

Fig. 2 Axial CECT section of the head and neck showing a large hyperintense mass extending from the level of the posterior border of the the sternocleidomastoid muscle to the prevertiberal facia.

\section{Surgical management}

The patient underwent surgical exploration of the left side of neck and excision of the mass via a elliptical incision along the anterior border of the right sternocleidomastoid muscle. The cyst wall densely adherent to sternocledomastoid muscle and ansa cervicalis. The cyst wall extended up to prevertiberal fascia. Due to its wide extension and vital tissue contiguity cyst wall carefully dissected from vital structures but complete excision was not possible. During dissection transverse cervicalis and facial vein were sacrificed. Contents of the cyst leaked intra-operatively towards the final phase of the dissection but near complete removal of the wall of the mass was achieved. Macroscopically the specimen measured approximately $15 \mathrm{~cm}$ in length. All the important nerves and arteries encountered during the dissection were seen and try to preserved.

Complete surgical excision of cystic hygroma here was not possible due to anatomical location and extensive infiltration but curate and 5\% Povidoneiodine wash done was done of inner lining of remnant part of cystic hygroma. Post operative period remain uneventful. Histological examination revealed cystic spaces lined with flat endothelial-like cells consistent with a diagnosis of cystic hygroma. 


\section{JMSCR Vol||06||Issue||08||Page 1108-1111||August}

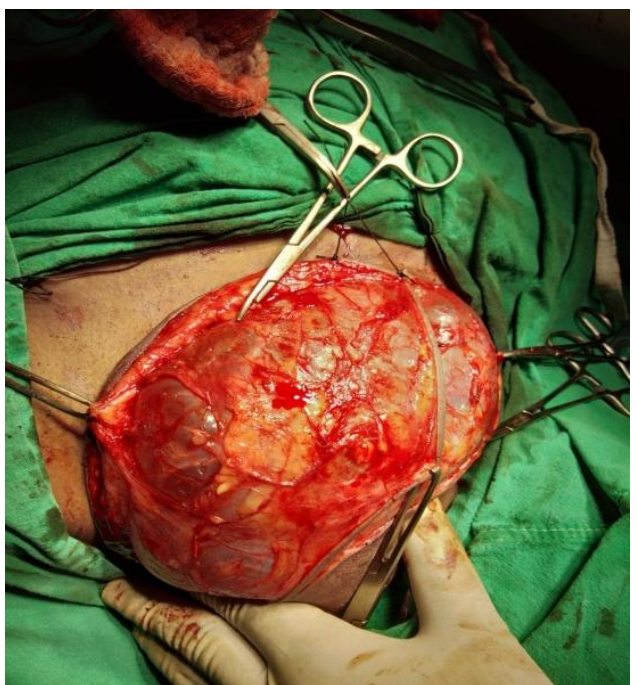

Fig. 3

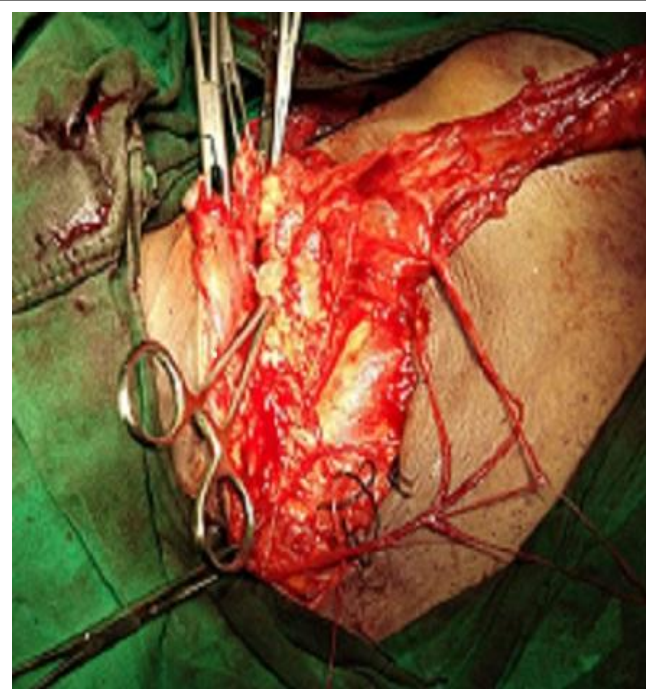

Fig. 4

Intra operative image of cystic hygroma after raising skin flap (Fig.3) dissection and preservation of ansa cervicalis (Fig. 4)

\section{Post-operative period}

Post-operatively the patient recovered well with no signs of any neurological or muscular dysfunction there is no significant complain or sign of any recurrence noted during follow up to 6 months.

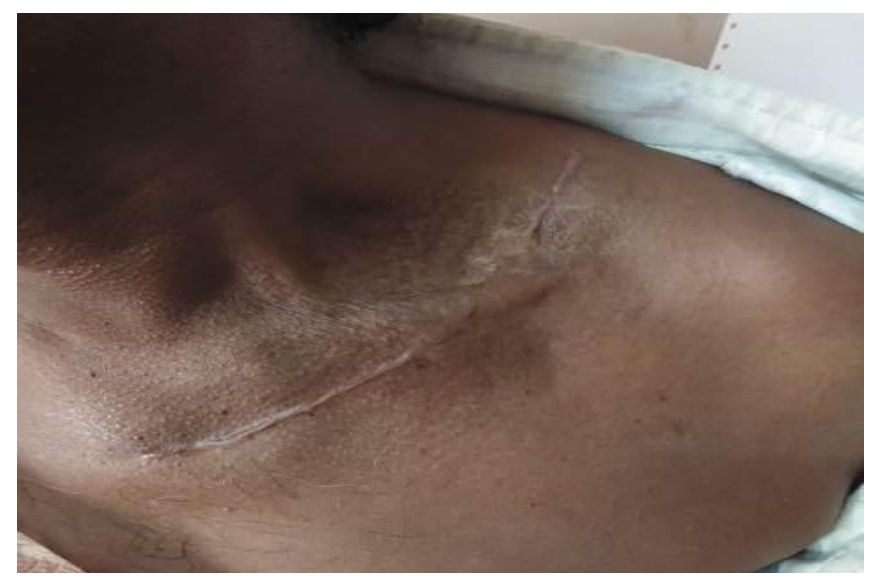

Fig. 5

\section{Discussion}

In this case the patient have cosmetic problem no other complain. En block surgical excision has been considered here. Other treatment option is sclerotherapy ${ }^{4}$, although sclerotherapy is not very effective recurrence is very common, post sclerotherap surgical plane destroyed which makes more difficult surgical excison ${ }^{5}$. In this case, it was thought that the ideal treatment would be complete surgical excision as multiloculated cystic hygroma may not respond to sclerotherapy.
Recurrence is also depend on anatomical location and extension of tumour ${ }^{6}$

\section{Reference}

1. Ethunandan M, Mellor TK. Haemangiomas and vascular malformations of the maxillofacial region-a review. British Journal of Oral and Maxillofacial Surgery. 2006 Aug 1;44(4):263-72.

2. Al-Dajani N, Wootton SH. Cervical lymphadenitis, suppurative parotitis, thyroiditis, and infected cysts. Infectious disease clinics of North America. 2007 Jun 1;21(2):523-41.

3. Koeller KK, Alamo L, Adair CF, Smirniotopoulos JG. From the Archives of the AFIP: Congenital cystic masses of the neck: Radiologic-pathologic correlation. Radiographics. 1999 Jan;19(1):121-46.

4. Gaunt M, Tang T, Walsh S. General Surgery Outpatient Decisions. Radcliffe Publishing; 2008.

5. Fliegelman LJ, Friedland D, Brandwein M, Rothschild M. Lymphatic malformation: predictive factors for recurrence. Otolaryngology-Head and Neck Surgery. 2000 Dec;123(6):706-10. 
6. Zhou Q, Zheng JW, Mai HM, Luo QF, Fan XD, Su LX, Wang YA, Qin ZP.

Treatment guidelines of lymphatic malformations of the head and neck. Oral oncology. 2011 Dec 1;47(12):1105-9. 